\title{
COMMENTARY
}

\section{Global Population Size and the United Nations' Sustainable Development Goals}

Partha Dasgupta *

\section{INTRODUCTION}

Of all the factors influencing humanity's demand for the biosphere's products, the global population size is conspicuous by its absence in ecological economics. In this Note I redress the neglect ever so slightly by reflecting on the way the subject has been both touched upon and avoided in international discourse. For illustration I focus on sub-Saharan Africa. Today the region is home to about 13 per cent of the world's population. Proportionately that is small, but it won't remain small unless the region engages seriously in matters relating to family planning. The opportunities being missed there speak to the enormous cost that is likely to be faced by African societies in future years. The problems looming there are mirrored in those that continue to face parts of South Asia.

In a well-known paper Ehrlich and Holdren (1971) noted that the biosphere responds to the demands we make of it, not to rates of change in those demands nor to rates of change in the rates of change in those demands. Their observation has not had much influence on either economics or demography; nor has it had any influence on the popular mind. That the growth rate of the global population has been declining in recent years is seen among development experts as a hopeful sign of a transition to sustainable development (World Bank 2016). In fact it says little about the prospect of realizing sustainable development. Under foreseeable technological developments and institutional arrangements, a long-run population of $10-11$ billion can be expected to make far greater

* University of Cambridge, The Old Schools, Trinity Ln, Cambridge CB2 1TN, UK; pd10000@cam.ac.uk

Copyright (C) Dasgupta 2018. Released under Creative Commons AttributionNonCommercial 4.0 International licence (CC BY-NC 4.0) by the author.

Published by Indian Society for Ecological Economics (INSEE), c/o Institute of Economic Growth, University Enclave, North Campus, Delhi 110007.

ISSN: 2581-6152 (print); 2581-6101 (web).

DOI: https://doi.org/10.37773/ees.v1i1.6 
demands on the biosphere than one of, say, 3 billion. ${ }^{1}$ Declines in fertility rates in India and Bangladesh, for example, do not speak to the socioeconomic difficulties people in the region face on account of the high rates they experienced in the past.

A number of books have recently drawn attention to the remarkable gains in the average living standard that the world has enjoyed during the past century. They have pointed to advances in scientific knowledge and the accumulation of manufactured and human capital, but they have mostly ignored the state of the biosphere and its trends accompanying economic progress (Micklethwait and Wooldridge 2000; Ridley 2010; Deaton 2013; Lomborg 2014; Norberg 2016). But humanity's future will be shaped by the portfolio of assets we choose to hold and the balance we strike between them and the size of our population. It should be a concern today that the enormous economic success the world has enjoyed in recent decades may be a down payment for future failure.

Figure 1: Total population by region, 2015-2100

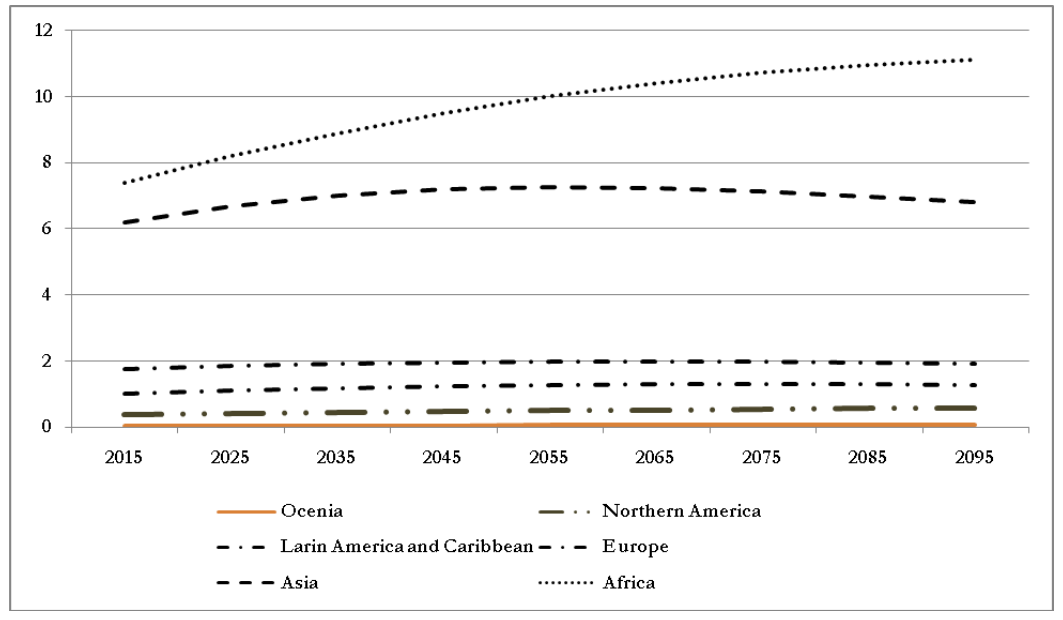

Source: UN (2017)

${ }^{1}$ If 3 billion reads unrealizably small, it is worth noting that the global population as recently as 1950 was 2.5 billion. 


\section{UNMET NEED AND FAMILY PLANNING PROGRAMMES}

In year 2100, the United Nations (UN) projects, the world population will be 11.2 billion (Figure 1). More than three-quarters of the increase from today's 7.4 billion is expected to be in sub-Saharan Africa, where the population in 2100 is projected to rise from today's approximately 1 billion to 4 billion. Attempts to raise incomes there even to the current global average $[15,000$ (international]) in the face of a three-billion rise in numbers will require an increase in the region's annual output from $\$ 3.5$ trillion to $\$ 60$ trillion. That rise, assuming that it is possible, is likely to have severe consequences for the continent's ecology, contributing to further societal conflicts there and greater attempted population movements both within the region and out of it. The UN's Sustainable Development Goals (SDGs) are reticent about population, and yet it is inconceivable that they can be met without addressing the subject.

Today the world community conceptualizes family planning programmes in terms of women's reproductive rights. The Programme of Action of the International Conference on Population and Development (UNFPA 1995), a landmark document, has been the basis on which family planning programmes are now framed and implemented. Unfortunately, there are two problems with the framework.

The first lies in the restrictive sphere to which 'rights' have been consigned. Because the biosphere is in large measure a global common, additional human numbers give rise to detrimental externalities, and the rights of those who are adversely affected by new births-especially, perhaps, people in the future- are ignored. No doubt one way to dampen the clash of rights is to reduce environmental externalities, but so long as there are no collective agreements on our use of the biosphere the clash will remain. ${ }^{2}$

The other problem has to do with the way success in implementing family planning programmes is measured. The UNFPA (1995) took it that family planning and reproductive health policies should address 'unmet need', meaning that they should be made to serve women aged 15-49 who are seeking to stop or delay childbearing but are not using modern forms of contraception.

There are deep problems here. Unmet need for modern contraceptives as calculated from responses to survey questions is based on the respondent's expressed wants for biological children. The need for family planning programmes is then inferred from the unmet need. But in matters of life

\footnotetext{
2 Sen (1982) likens the emission of persistent pollutants to torturing future people. The clash between reproductive rights and adverse environmental externalities allied to new births is at its most striking under his reading.
} 
and death needs assume an independent status-they even serve as the basis on which commodity rights are founded. The philosopher David Wiggins has argued that a statement of the form 'person A needs commodity $\mathrm{X}^{\prime}$ is tantamount to a challenge to imagine an alternative future in which A escapes harm without X (Wiggins 1987, 22). Expressed wants (or desire) for children may not adequately convey her need for family planning, that is, for her own best interests. A poor woman living in a setting where she is more or less obliged to have sex and suffering from iron deficiency has a need for contraception for her own benefit that could remain undetected in her responses to questions on the wants she expresses for biological children. To infer needs solely from wants is therefore to undervalue the significance of family planning. Moreover, none of the survey questions that are in current use is conditioned on the behaviour of others. That runs counter to the fact that our preferences are socially embedded: we look to see what others do before we ourselves choose our doings. This interconnectedness of people in society is as true in fertility desires as it is in consumption practices. Periodically they are expressed in fads and fashions. The line joining need to expressed wants is tortuous.

Fabic et al. (2015) define 'total demand' for modem contraception to be the number of women who want to delay or limit childbearing (that is, the sum of contraceptive users and women with unmet need). The role of family planning, the authors argue, is to supply that demand. The suggestion is that the success of family planning should be measured by the ratio of family planning users to the total demand. The UN have adopted this measure in their SDG 3.7.1. The measure is known as 'demand for family planning met with modern contraceptive methods' or, for short, 'demand satisfied'. Formally, if $X$ is the number of women aged 15-49 who are users of modern contraceptives, $Y$ is the number of women with unmet need, and $Z$ is total demand for modern contraception, then $Z=X+Y$, and the UN's 'demand satisfied' is $X / Z=X /(X+Y)$.

Reproductive rights are at the heart of $X / Z$, which is its attraction. The indicator reflects voluntarism, rights and equity, informed choice, and the imperative of satisfying individuals' and couples' own choices with regard to the timing and number of children.

But there are problems. The use of $X / Z$ as the measure of success could create perverse incentives among programme managers. A programme's performance would improve if more women were to declare that they want to get pregnant. So long as women want many children, $Y$ (unmet need) remains small, and therefore $Z$ (total demand) is only marginally greater than $X$ (the number of modern contraceptive users). The country scores well in the indicator 'demand satisfied', and appears not to need further 
family planning programming. The success could mask a situation where contraceptive use is low and stagnant and high fertility rates persist. Moreover, as noted above, fertility preferences (which contribute to the measurement of $Y$ ) are themselves influenced by the behaviour of others. $Y$ could therefore be small in a society that harbours another equally stable state of affairs in which $Y$ is large. ${ }^{3}$

\section{AN EXAMPLE}

Niger's total fertility rate (TFR) is currently 7.6. Only 12 per cent of married (or in union) women are estimated to use modern methods of contraception. But unmet need for family planning is low: among married (or in union) less than 17 per cent women say they do not wish to get pregnant and are not using contraception. They also say their desired number of children is 9.5 . Income per capita there is $\$ 940$ international, meaning that the average person's income is only a bit above the internationally accepted level of poverty (1.90 dollars). The country's population in 2012 was 17.6 million and is projected to rise in 2050 to over 72 million. It is more than difficult to imagine what resources will be available for the millions who will be born there in the coming years. And, yet, inferring 'unmet need' from expressed desires and using that to give expression to reproductive rights could even suggest that married (and in union) women in Niger should be helped to raise their fertility. The clash of rights is self-evident.

\section{UNDERVALUATION OF FAMILY PLANNING}

The concept of reproductive rights as currently framed and put to use by the UN undervalues family planning. There are collective benefits to be enjoyed if members of a community are enabled through discussions to alter their fertility desires in a coordinated manner. Family planning can help to bring about changes in the norms that guide personal desires and behaviour. Our analysis doesn't run against rights as a plank for family planning; it expands the sphere in which rights are acknowledged, protected, and promoted.

\footnotetext{
${ }^{3}$ Formally, I am speaking of coordination games, harbouring multiple equilibria: if all other households are large, the representative household plans for a large family; but if all other households are small, the representative household plans for a small family. And it may be that all households would prefer the latter outcome to the former.
} 


\section{ACKNOWLEDGEMENTS}

This Note has been prepared for the Inaugural Issue of Ecology, Economy and Society. The demographic evidence presented here is drawn from Dasgupta and Dasgupta (2017) and I am grateful to Aisha Dasgupta for the many discussions we have had on the subject. The views expressed here are, however, entirely mine.

\section{REFERENCES}

Dasgupta, A. and P. Dasgupta. 2017. "Socially Embedded Preferences, Environmental Externalities, and Reproductive Rights." Population and Development Review 43 (3): 405-441. https://doi.org/10.1111/padr.12090

Deaton, A. 2013. The Great Escape: bealth, wealth, and the origins of inequality. Princeton, NJ: Princeton University Press. https://doi.org/10.1515/9781400847969

Ehrlich, P.R. and J.P. Holdren. 1971. "Impact of Population Growth." Science 171 (3977): 1212-1217. https://doi.org/10.1126/science.171.3977.1212

Fabic, M.I., Y. Choi, J. Bongaarts, J.E. Darroch, J.A. Ross, J. Stover, A.O. Tsui, J. Upadhyay, and E. Starbird. 2015. "Meeting Demand for Family Planning Within a Generation.” Lancet 385 (9981): 1928-1931. https://doi.org/10.1016/S01406736(14)61055-2

Lomborg, B. ed. 2014. How Much Have Global Problems Cost the World? A Scoreboard from 1900 to 2050. Cambridge: Cambridge University Press.

https://doi.org/10.1017/CBO9781139225793

Micklethwait, J. and A. Wooldridge. 2000. A Future Perfect: The Challenge and Promise of Globalization. New York: Random House.

Norberg, J. 2016. Progress: Ten Reasons to Look Forward to the Future. London: One World.

Ridley, M. 2010. The Rational Optimist: How Prosperity Evolves. London: 4th Estate. https://doi.org/10.1016/S0262-4079(10)61556-4

Sen, A. 1982. "Approaches to the Choice of Discount Rates in Social Benefit-Cost Analysis." In Discounting for Time and Risk in Energy Policy edited by R.C. Lind. Baltimore, MD: The Johns Hopkins University Press.

UNFPA. 1995. Programme of Action of the International Conference on Population and Development. New York: United Nations Population Fund.

UN. 2017. World Population Prospects: The 2017 Revision. New York: United Nations, Department of Economic and Social Affairs, Population Division.

Wiggins, D. 1987. “Claims of Needs.” In Needs, V alues, Truth. Oxford: Basil Blackwell.

World Bank. 2016. Development Goals in an Era of Demographic Change. Washington DC: World Bank. 